https://jurnal.ugm.ac.id/rubikon

\title{
BANGTAN SONYEONDAN (BTS) AS NEW AMERICAN IDOL
}

\author{
Ade Nine Suryani \\ e-mail: adeninesuryani30@gmail.com
}

\begin{abstract}
South Korean pop songs or colloquially K-pop has spread globally. America also has a massive impact on this K-pop wave phenomenon. America now gives its enormous attention to the Bangtan Sonyeondan group or BTS group because this K-pop group is prevalent and becomes the new idol in America. In the beginning, K-pop is not successful, but until BTS comes and becomes a global sensation there. This paper tries to analyze which factors enable BTS to be the new idol in America. The writer uses a qualitative method to conduct the data and reception theory from Stuart Hall in the analysis. This analysis results in BTS, as the most popular K-pop group in America nowadays, has two factors that enable them to dominate American fans. The first one is through their androgyny physical appearance that redefines American traditional macho masculinity. The second one is through messages in their songs that raise social issues and mental health problems, helping their fans survive in their harsh lives.
\end{abstract}

Keywords: BTS; decoded; encoded; $k$-pop; reception theory

DOI $\quad$ : https://doi.org/10.22146/rubikon.v6i1.61489

Available at https://jurnal.ugm.ac.id/rubikon/article/view/61489

This work is licensed under a Creative Commons Attribution-ShareAlike 4.0 International License

\section{INTRODUCTION}

South Korean popular music (known colloquially as K-Pop) is a musical genre that incorporates various styles. Actually, K-pop constitutes the hybridity or combination between modern Korean style in performance such as visualization, dance move, fashion, and talents from the idol with Western sound and African-American influence such as Hip-hop, R\&B, Jazz, disco, etc. (Leung, 2012, pp. 2-3).
Article information

Received: 15 January, 2019

Revised:29 January, 2019

Accepted: 13 February, 2019
From the beginning K-pop was not really successful in penetrating America especially in North America until singer Park Jae Sang or his stage name as PSY made his song booming in some countries, "it penetrated America, Kpop was successful in North America because of "Gangnam Style" song from PSY" (Dal, 2008, p. 405). After this success, other K-pop groups such as Big Bang, Super Junior, Girls Generation, EXO, and lately BTS start their debut in America. 
Recently, the K-pop group that has a massive success in penetrating the American music market is "Bangtan Sonyeondan" or BTS. BTS is a boy K-pop group that debuted in 2013. There are seven members of this group. They are RM or Kim Nam Joon as the leader and main rapper, Kim Seok Jin as visual and subvocalist, Suga or Min Yoongi as a lead rapper, Jung Ho Seok or J-Hope as rapper and dancer, Park Jimin as sub-vocalist and dancer, Kim Taehyung as sub-vocalist and dancer, and Jungkook as the golden youngest member or "golden maknae" in Korean because he is the multi-talented person as the main vocalist, dancer and also sometimes rapper. At the beginning of their journey, being a boy group in South Korea is tough. It is because they are from a small entertainment label named Big Hit Entertainment. Commonly, in South Korea, if a K-pop group is from a small entertainment label, it is impossible for the group to compete with other groups from big and notable entertainment labels such as the so-called big three entertainment as YG Entertainment, SM Entertainment, and JYP Entertainment. They were ignored for two years because of it and almost banned their group. However, they still tried to stay together in reaching their dreams as singers. Finally, they achieved their dream through hardship and showed their talent by performing and winning in Billboard Music Awards as Top Social Artist and Top Duo Group category.

This K-pop boy band group started entering the Billboard chart through their song "I Need You" released in 2015. After their first step entering the Billboard music chart Hot 100, their next songs improve extremely into the first number on iTunes chart, such as DNA in 73 countries in the world (IPac, 2017, December 20). Their performance also helped their success and their win in Billboard Music
Awards in 2017, 2018, and 2019 as Top Social Artist, which back then was won by Justin Bieber from 2011 until 2016. From their first performance in 2017, they started to be the global phenomenon and they started to be invited in many variety-shows in America, such as Jimmy Kimmel, The Ellen Show, Good Morning America, and others. Besides performing in many talk show and awards in America, BTS also won some awards category such as Top Social Artist (2017, 2108, 2019) and Top Duo Group category (2019) in Billboard Music Awards, Favorite Social Artist, Tour of the Year and Favorite Top Duo or Group Pop/Rock in American Music Awards, Fan Fave Duo or Group (2018), Best Boy Band (2018 and 2019) and Best Fan ARMY (2019) in iHeartRadio Music Awards, etc. They are also successful with their world tour "Love Yourself" and "Speak Yourself" in America recently. It can be seen from their ticket that has been sold out in few minutes in tickets sales such as in Oracle Arena, Oakland; Staples Center, Los Angeles; Rose Bowl Stadium, Los Angeles; City Field, New York; Metlife Stadium, New Jersey; and Soldier Field, Chicago (BTS World Tour 2018-2019).

Based on Stuart Hall, traditionally, the process of communication is circulated between the sender/message/receiver. The sender here is the producer or the encoder that produces a message and has his own assumption about the audience as the receiver or the decoder; "They draw topics, treatments, agendas, events, personnel, images of the audience, 'definitions of the situation' from the wider socio-cultural and political system of which they are only a differentiated part" (Hall, 1973, p. 387). A message then can be defined or has an effect when it has been perceived as a meaningful discourse and meaningfully decoded by the audience. That de-code has 
effects such as influencing, entertaining, instructing, or persuading with complex perceptual, cognitive, emotional, ideological, or behavioral consequences. However, in decoding a message, it has a different response from the audience.

There are four stages of the communication process which are the crucial and distinctive moment in determining whether the message can be fully decoded by the audience or not. They are production, circulation, distribution/consumption, and reproduction stage (Hall, 1980, p. 117). The first stage is the production stage. It is where the encoding message takes place. The producer encodes the message by drawing the society's dominant ideologies, such as the dominant beliefs and values. The second stage is the circulation stage. It is the manner how the message is transmitted. How the circulated message influences the audience's receptions. The third stage is the distribution or consumption stage. This is the decoding/interpreting process toward the message by the audience which is a really complex process. The last is the reproduction stage. After the audience has decoded or interpreted the message based on his or her experience, belief, and value, he or she gives a reaction after consuming the message in this stage.

In the decoding process, there are three types of reception of the audience. First is dominant or preferred reading. It is when the audience accepts the message clearly and the same with the purpose of producer encodes if the audience is in the same culture. Thus, the message theme is relevant to the audience. The second is negotiated reading. This reading is when the audience accepts what the producer encodes through the text or message partially and the audience has her or his view in decoding the message. The audience can have different culture but they try to accept what the producer wants to deliver via text or message. However, this attempt is done only when it can still be accepted by their ideological thought. The last one is the oppositional reading. This reading occurs when the audience rejects the preferred reading and creates their own meaning of the message or text because of the different cultures, beliefs, and values. It occurs when the theme of the message is controversial (Hall, 1973, pp. 13-19).

This analysis tries to disclose the audience reception on BTS - as Korean boy groupimpact in American society. It means that this analysis using a transnational perspective that studies America by looking beyond its border. Transnational perspective offers the crossroads result in the process from historical roots of multidirectional flows of people, ideas, good, social, political, cultural, etc. As Fishkin stated that this crossroad might be "outside the geographical and political boundaries of the United States as inside them" (2005, p. 22).

\section{DISCUSSION}

\section{The Appealing Appearance of BTS Members to the American Audience}

It is a fact that the competition among the idol group in South Korea is very tight. Once someone becomes an idol in a boy group, they have to maintain appearance because this is the priority seen by fans preceding the talent and the work. Their first debut event is when they attended and performed at Billboard Music Awards. They are found attractive in America because of their different physical appearance and they also redefine American masculinity. In that event, they wore a black suit with accessories such as necklace, ring, and earrings 
(as seen in Figure 1), and lately, they still raise the biggest fan in America with their song
"Boy With Luv" ft. Halsey in the very feminine atmosphere (as in Figure 2).

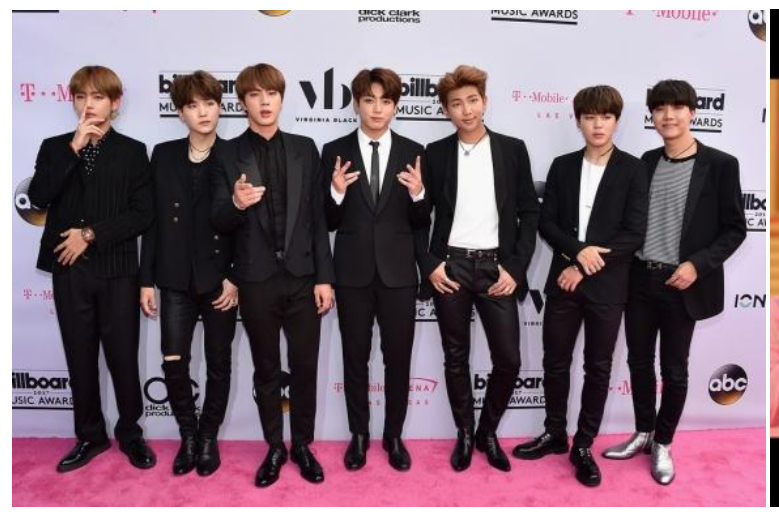

Figure 1: BTS Red Carpet at Billboard Music Awards (Shearer, 2017)

In their song concept and performance, they can wear pink suits, accessories such as ring, necklace, and earring, even makeup and they also have no beard, flawless skin, and small face while American masculinity traditionally deals with macho-masculine such as in Marvel's heroes movie. They leave the typical "toxic masculinity" which is associated with "suppressing emotions or masking distress," "maintaining an appearance of hardness" and using "violence as an indicator of power," as conceptualized by the New York Times" (Pham, 2019). If a man does not possess those characteristics, it can be concluded that he is feminine or weak in western culture. In contrast, according to CedarBoughSaeji, a Korean culture professor at Indiana University Bloomington, in Korea, there is a term named "kkonminam" means "flower boy" which refers to "androgyny" where a young man who gives more attention with grooming and fashion. If a man is called "kkonminam" so he will be happy because it is a compliment.

In America, neither young guys nor the western pop stars apply makeup. It makes BTS' appearance more attractive, although it is girly. It can be seen from the rise of their fans'

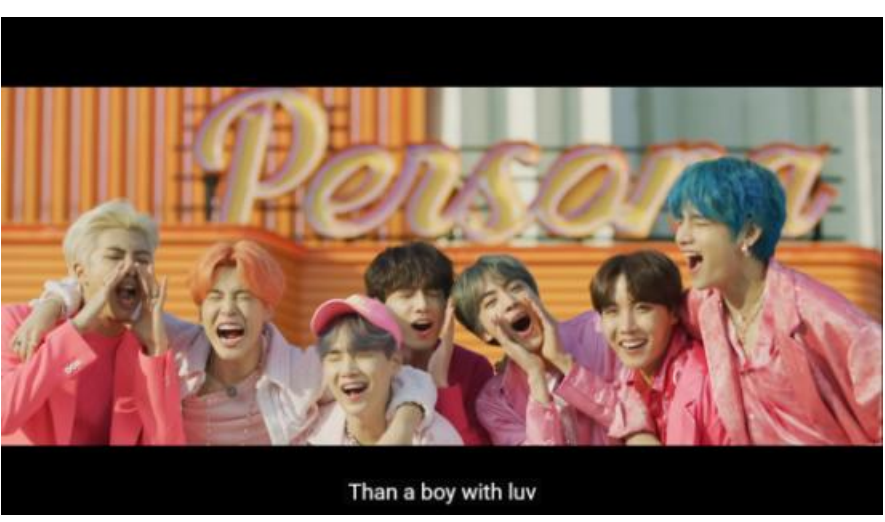

Figure 2: BTS Music Video Ft. Halsey "Boy

With Luv" (Big Hit Label, 2019)

fandom there. For instance, Marlena. She is one of BTS fans. She tells Style Caster (style news, fashion trends, and beauty tips platform): "I found them more appealing. There was more effort behind their outfits. There was more thought into how they looked, whether it's their styling or their makeup. I didn't see it as a weird thing at all" (Pham, 2019). Thus, there is a change in seeing the typical traditional masculinity in American society today, especially the young generation who really falls to BTS' attractive appearance.

\section{The Attractiveness of BTS' Story to American Audience}

BTS constitutes seven members and some of them write and produce the songs. Being idol in South Korea means they have to be able to dance and sing but it is not a priority that the idol has to be able to write and produce the songs. In contrast, BTS, from the beginning, have their self-produced songs mostly by RM, Suga, and J-Hope. They are BTS song lyricists and producers. However, the rest of the members also have the solo songs that they write mainly in the "Wings" album released in 2016 which told about their feeling at that time, especially their struggle to pursue their dream 
as singers and idols in South Korea. Their songs are based on what they experience in their life.

In the first album, they were in the high school era so it was about them being teenagers that experienced love and did not know about their dreams (Skool Luv Affair). Then in the next album, it is mostly about their dream that seems too hard to reach and support each other to achieve it (The Beautiful Moment in Life part $1 \& 2$ ). They also share their hardship to accept themselves and recently, they release their acceptance about themselves in their album (Love Yourself and Persona). They write and share their own story how they reach their dreams and accept themselves.

BTS also promotes the 'Love Myself' campaign that aims for anti-violence and selfconfidence in collaborating with UNICEF and becoming a youth representative at the United Nations. Their fans in America fall into BTS because of the way BTS members share their stories through good music and the right message mostly criticizes social issues such as social pressure and depression. There are so many lyrics about it such as in Am I Wrong song where "BTS call out socially unconscious people, confronting that the world is going crazy in the lyric "If what you see on the news is nothing to you... you're not normal" and The Last song by Suga," he addresses mental illness in a frank and honest manner which is uncommon in K-pop. The lyric is "On the other side of the famous idol rapper stands my weak self, it's a bit dangerous/depression, OCD, they keep coming back again from time to time" (SBS Pop Asia HQ, 2018).

These are what their fans (called ARMY) said about their music lyrics. First, came from their fans in City Field concert on 16th
November 2018 through MTV news interview. Edison Zheng, ARMY:

I started listening to BTS last summer and I was infatuated with the choreography, I just decided that I wanted to try dance. And now like two years later I'm obsessed with them. I'm a teenager and I struggle with a lot of emotional stuff, like personal problems. Music nowadays, it's cool, and it's good, but there is nothing like BTS. It directly talks to a teenager. Depression, anxiety, social problems, all that, I suffer from, I deal with. Every day at my high school, during lunch period or gym, I would go upstairs to this empty room, and I would dance there for 45 minutes to an hour, every single day (MTVNews, 2018, 05:29-06-06).

Emy Ibarra, founder of US BTS ARMY (fan club):

To me their music is everything. It came at a point in my life when I did not know who I was as person, I did not know what I wanted to do with my life, but to have these boys just come out be like, hey, it's okay, you'll figure it out, don't worry about it, just do you and do the best that you can, was really, really great (MTVNews, 2018, 06-06:06-24).

Second, a fan who signs a petition in change.org website to Big Hit Entertainment and Powerhouse Life which asks BTS to perform in Southeast USA said that she wanted this K-Pop group to perform there because this $\mathrm{K}$-pop group has helped her in a hard time.

I'm signing because $\mathrm{i}$ am a hard core BTS fan. I am 54 years old and it has been my dream the last three years to see BTS in concert. My daughter loves BTS also and I would love to be able to attend a BTS concert with her. I love these boys with all my heart. And their music has pulled me through some really hard times. I have watched all their videos since their debut and pray that I will get to see them in person. They are very considerate of their 
fans. It is easier for us to go to Atlanta Georgia than any of the other concerts. Please bring them to Atlanta for their southern fans too (Elliot, 2018).

From what they admit as fans, it can be seen that only BTS can get their attention than the other K-pop groups. It is because BTS has their style in delivering their authentic message that they experience from their life through their music which raises a different issue as $\mathrm{K}$ pop idol brings commonly about love. Thus, it can be seen that BTS is like the savior, the hero who helps them survive with their social problems and mental illness since it is a big issue in America. If it is related to the mental health issue, in America, anxiety disorders are the most common mental illness. It affects 40 million adults in the United States, 18 years old and older (18.1\% of the population) every year (Anxiety and Depression Association of America, n.d.).

Depression, in general, about 1 out of every 6 adults will have depression at some time in their life. It affects about 16 million American adults every year. Commonly, anxiety disorders often go hand in hand with depression. People who have anxiety disorders struggle with intense and uncontrollable feelings of anxiety, fear, worry, and/or panic, and people who have depression show more than just feeling down or having a bad day. It is a sad mood that lasts for a long time and interferes with everyday life (Centers for Disease Control and Prevention, n.d.).

\section{CONCLUSION}

BTS, as the new generation of K-pop group from South Korea, has become the new American Idol and has had a massive impact in America. Their good acceptance in this country has changed the perception of a part young generation in seeing masculinity in America and the view of K-pop culture itself through their androgyny appearance. In traditional American masculinity, males have to be macho but because of BTS, they redefine this masculinity with their flower boy appeal. Moreover, through their songs which lift about social problems and mental illness issue, they also become a hero and savior to give their fans strength in combating these issues, which is a crucial problem in America, especially in the young generation and adult.

\section{REFERENCES}

Anxiety and Depression Association of America. (n.d.). Facts and Statistics. About ADAA. Retrieved from https://adaa.org/about-adaa/pressroom/facts-

statistics\#: :text=Anxiety\%20disorders\% 20are $\% 20$ the $\% 20$ most, of $\% 20$ those $\% 20$ s uffering\%20receive\%20treatment.

Big Hit Label. (2019, April 12). BTS Boy with Luv (Feat. Halsey) Official MV [video] YouTube.

https://www.youtube.com/watch?v=XsX $3 \mathrm{ATc} 3 \mathrm{FbA}$

BTS World Tour. (2018-2019). Big Hit Entertainment. Retrieved December 6, 2019, from http://ibighit.com/bts/eng/tour

Centers for Disease Control and Prevention. (n.d.). Mental health conditions: depression and anxiety. CDC. Retrieved from

https://www.cdc.gov/tobacco/campaign/ti ps/diseases/depression-anxiety.html

Dal, Y. J. (2018). An Analysis of the Korean Wave as Transnational Popular Culture: North American Youth Engage through Social Media as Tv Becomes Obsolete. 
International Journal of Communication, 12. 404-422.

Elliot, A. (2018). Re: BTS Concert in Southeast USA [Website comment]. Retrieved from https://www.change.org/p/bighitentertainment-bts-concert-in-southeastusa-58aa6761-e290-4772-9579$46717950 \mathrm{ab} 24 / \mathrm{c} / 735385104$

Fishkin, S. F. (2005). Crossroad of Cultures: The Transnational Turn in American Studies: Presidential Address to the American Studies Association, November 12, 2004. American Quarterly 57(1), 17-57.

Hall, S. (1973). Encoding and Decoding in the Television Discourse. In A. Gray, J. Campbell, M. Erickson, S. Hanson, \& H. Wood (Eds.), CCCS Selected Working Papers, (386-398). Routledge.

Hall, S. \& Hobson, D. (Eds.). (1980). Culture, Media, Language. Routledge.

IPac. (2017, December 20). The US Embraces KPop Music. IPAC. Retrieved December 7 , 2019 , from https://ipaction.org/blog/the-usembraces-K-pop-music/

Leung, S. (2012). Catching the K-Pop Wave: Globality in the Production, Distribution, and Consumption of South Korean Popular Music. Senior Capstone Projects. Retrieved from http://digitalwindow.vassar.edu/senior_ca pstone/149

MTVNews. (2018, November 16). BTS ARMY: Inside the World's Most Powerful Fandom MTV News [video]. Youtube. https://www.youtube.com/watch?v=Ersjs FpIz4s\&t=6s
Pham, J. (2019, November 8). BTS is Redefining What It Means to be Masculine \& Attractive in America. Style Caster. Retrieved December 7, 2019, from https://stylecaster.com/btsmasculinity-america/

SBS Pop Asia HQ. (2018, March 16). 12 BTS Songs with Strong Social Messages. SBS. Retrieved December 7, 2019, from https://www.sbs.com.au/popasia/blog/20 18/03/16/12-bts-songs-strong-socialmessages

Shearer, J. (2017). BTS [Photograph]. Billboard. Retrieved from https://static.billboard.com/files/media/bt s-bbmas-2017-carpet-1548-1024x677.jpg 